\title{
On the way toward the sector spanning agrifood process traceability
}

\author{
Mónika Varga ${ }^{1}$, Béla Csukás²
}

\section{N F O}

Received 5 April 2010

Accepted 19 May 2010

Available on-line 31 May 2010

Responsible Editor: K. Rajkai

\section{Keywords:}

agrifood processes, process networks, traceability, sector spanning, process modeling

\begin{abstract}
$\underline{\text { A B S T R A C T }}$
Having overviewed the state-of-art in agrifood traceability, the paper focuses on the multiscale modeling of the underlying problems. The main conclusion is, that there are not really workable sector spanning traceability methods, but the field experts and the computer modeling community seems to be prepared to develop quite new tools in the near future. According to our opinion, the sector encompassing IT centers ought to find a reasonable compromise between the "Schylla" of the simple, step by step passing of traceable unit IDs for the neighboring actors, and the "Carybdis" of accumulating enormously huge databases, containing every relevant data of the actors. The future role of the sector spanning, outside intelligent centers is to provide traceability and trackability service for the actors on cooperative basis of the mutual interests. In addition, the centers have to support the supply chain and value chain management, as well as the work of the authorities, that are responsible for the human health. Present study provides a good basis to our future development of a really sector spanning method. In a following paper we shall outline a sector spanning system on the basis of the Direct Computer Mapping based simulation methodology, in detail.
\end{abstract}

\section{Introduction}

Traceability became generally known by the bovine spongiform encephalopathy, by the dioxin scandal, or by melamine impured milk. Since then, an increasing part of the consumer society has been making demand for more reliable food products in the market. This requires transparent technologies in every single step of the agricultural, food industrial and commercial processes.

Considering the increasing necessity, the formalization of the quality (and traceability) knowledge in enterprises was clearly determined by Kim (Kim et al., 1995). They decompose the quality into "component competency questions" that general enough to motivate evaluation of quality representations within an enterprise. The authors consider traceability as the sub-domain of the quality ontology. They describe the fundamental and necessary characteristics of a proper traceability system, which is the ability for the identification of both the products and the processes. Authors translate the detailed competency questions into the predicate logic and implement it in Prolog declarations.

Traceability in the literature is defined in several ways. For example, according to ISO 9001:2000 (Quality Assurance Standard), traceability is "the ability to trace the history, application or location of that, which is under consideration". In another aspect, ISO 8402:1994 defines traceability as "the ability for the retrieval of the history and use or location of an article or an activity through a registered identification". According to American Production and Inventory Control Society, traceability is the "registering and tracking of parts, processes and materials used in production, by lot or serial number".

Golan et al. define traceability in terms of depth (levels of the supply chain), breadth (attributes traced) and precision (level of detail) (Golan et al., 2004). Breadth means the amount of information, collected during the internal processes. Depth refers to the length of information that can be tracked along the actors. Finally, precision means the validity of information and the degree of assurance.

\footnotetext{
${ }^{1}$ Mónika Varga

Kaposvári Egyetem, 7400 Kaposvár, Guba S. út 40., Hungary

varga.monika@ke.hu

²éla Csukás

Kaposvári Egyetem, 7400 Kaposvár, Guba S. út 40., Hungary

csukas.bela@ke.hu
} 
Kim et al. in their early work (Kim et al., 1995) formulate three main points, which determine the success and effectivity of a traceability system: the compatibility, the data standardization and the definition of Traceable Resource Unit. According to their interpretation, TRU is the small enough unit of raw materials or products to follow them, as well as the big enough unit to manage it rationally. In common sense, TRU is a clearly defined amount of raw materials or products that are uniquely identifiable and traceable.

\section{Elements of the underlying methodologies}

\subsection{Identification methods}

Main identification methods in the food chains are the followings:

- Biological identifiers (e.g. DNA based);

- Optical identifiers (e.g. bar codes);

- RFIDs (radio-frequency identifiers); and

- BOKODE (imperceptible visual tags for camera based interaction from a distance).

\subsection{Analytical methods of identification}

There are many measurement techniques in natural and engineering sciences to identify components in food products.

Peres et al. review the modern analytical techniques, with special regards to molecular biology techniques (Peres et al., 2007). Applications of these technologies help to determine the plant or animal species, present in a foodstuff.

Standardized analytical methods are collected into an information table (63 methods) in the framework of TRACE project (http://www.tracefood.org/index.php/Tools:Standardized Analytical Methods). The more detailed consideration of this field is out of the scope of present work.

\subsection{Data communication techniques and methods}

This field represents the whole repertoire of the computer and internet communication. Next, the most important communication protocols, standards and architectures, regarding traceability will be overviewed, without the demand of completeness.

\section{$E D I$}

EDI can be defined as "The transfer of structured data, by agreed message standards, from one computer system to another without human intervention”. Most of the other definitions used are variations on this theme. EDI refers to the structured transmission of data between organizations, by electronic means. It is used to transfer electronic documents from one computer to another (e.g. from one actor to another actor). EDI makes possible the actors to replace bills of lading with EDI messages.

In a paper of Füzesi and Herdon, authors collected the existing EDI standards, their advantages and disadvantages, the cost of the applications, as well as the evolution of EDI (Füzesi and Herdon, 2007).

TraceCore XML

TraceCore eXtensible Markup Language is a possible standardized way of data exchange in the field of traceability. TraceCore XML makes possible to determine the identifying number, the origin, the place and time of processing, transportation and receive, as well as of the joining or splitting of connected processes, etc. The standard was developed in the framework of TRACE project (http://www.trace.eu.org) by the Traceability Systems Group. Participants of the group were the Central Science Laboratory (now The Food and Environment Research Agency), the FoodReg, the RIKILT Institute of Food Safety (Wageningen, NL), TraceTracker and many other institutes from this field. They determined the present version of the TraceCore XML schema after reviewing and taking into account suggestions from various food chain actors. TraceCore XML has several, sector specific 
versions, for example TraceHam, TraceFish, TraceChicken, TraceCereal, TraceHoney, TraceMineralWater, etc. It is a freely available standard.

\section{GS1 (formerly EAN.UCC) standard}

GS1 is an international association with the aim to develop and implement global standards and solutions to improve the efficiency of supply/demand chains, as well as traceability in the agrifood networks. The GS1 is the most frequently used standard system in the world. The association (http://www.gs1.org) was founded in 2005 to harmonize the work of the North American Uniform Code Council (UCC, formed in 1974) and the European Article Numbering Association (EAN, formed in 1977 by 12 European organizations, representing manufacturers and retailers).

The main activity of GS1 is the development of a harmonized system, based on a series of standards, designed to improve supply-chain management. The GS1 System is composed of four key standards:

- Barcodes (used to identify things automatically),

- eCom (electronic business messaging standards allowing automatic electronic transmission of data),

- GDSN (Global Data Synchronization standards) which allow business partners to have consistent item data in their systems at the same time, and

- EPCglobal (which uses RFID technology to track an item immediately).

The objective of the GS1 System is to make efficient the communication between the connected partners, by establishing a precise, but flexible method of unique identification of products and packages in both human and machine readable formats.

\section{Multi-scale system of the underlying problems}

We can distinguish three levels of the multi-scale systems in the field of information management. These traceability levels are the followings:

- internal (inside the actors with many field specific issues),

- external (between the actors, interoperability of the neighbors), and

- sector spanning (considering the whole network of chains, and interoperability of the sectors).

\subsection{Internal level systems}

\section{ERP based solutions}

There are numerous Enterprise Resource Planning softwares, which offer complex solutions for production control in food chains, related to the procurement, inventory, production, requirements planning, sales, traceability, quality management and laboratory information system.

The advantages of ERP systems are the integrated process management and the balance-like mapping of the materials in every single step of the production process, inside the actor's system. However, SMEs or private businesses are often not able to integrate such a complex and expensive system.

Herdon and Füzesi write about the characteristics of product tracing in ERP systems, regarding to the Hungarian meat sector, through the examination of CSB-System and Fókusz ERP system (Herdon and Füzesi, 2006).

\section{FMECA approach based solutions (HAZOP derivative)}

Bertolini at al. present an application of the industrial engineering tool, named Failure Mode Effect and Critical Analysis (FMECA) to manage the production processes of the food chain (Bertolini et al., 2006). Authors propose improvements of the applied method, considering the characteristics of the farming and the food industry. FMECA had been applied by the Ford Motor Company and was used as a US Military Standard for a long time. 


\section{MILP based batch dispersion model}

An example for batch dispersion model was published by Dupuy et al. through the example of a French sausage manufacturing company (Dupuy et al., 2005). Authors propose a mathematical (mixed integer linear programming) model and solve it with LINGO software. First of all, they interpret the definition of batch dispersion, derived from the definition of downward and upward dispersion. Downward dispersion is $\mathrm{X}$, if an identified quantity of a raw material is used in $\mathrm{X}$ end products. Upward dispersion of a finished product batch is the number of different raw material batches used to produce this batch.

\section{Fuzzy batches of the continuous production}

Skoglund and Dejmek discuss the problem of continuous liquid food processing (Skoglund and Dejmek, 2007). In this case, mixing zones and indistinct batch identities cause difficulties. Authors apply dynamic simulation to improve the management of batch identities in continuous production. They introduce the so-called fuzzy traceability concept. Authors simulate the process analogously to the Fick's laws of diffusion. As a conclusion, they find out, that traceability systems in continuous productions need further development.

\section{Causal diagram based dynamic analysis}

In a relatively early work of Minegishi and Thiel, authors analyze how system dynamics could contribute to improve the knowledge of the complex logistic behaviour of integrated food industrial processes (Minegishi and Thiel, 2000). Their developed model is based on the causal relations of the investigated system. The causal diagram based representation means the visualization of variables and their interactions, signed by arrows. Arrows could point out the cause (origin of arrow) and its direct effect (endpoint of the arrow).

\subsection{External level systems}

Jansen-Vullers et al. propose a gozinto graph model based approach to design an information system for trace the flow of goods (Jansen-Vullers et al., 2003). In this case, gozinto graph represents the materials along the production process, from the raw material to the end product. The complete graphical scheme is translated into a reference data model, which gives the basis of a traceability information system. Authors call the attention to a difficult problem. Accordingly, the production is organized in such a way, that several independent organizations are involved. This problem requires such a solution, which is compatible both in internal and external level. Authors apply the ProcessControl-Information (PCI) model from Bemelmans, to solve the problems in communication between the different layers (within the enterprise and between actors). They outline the idea of a lower level "institutional layer", which layer "covers all issues that are related to making the supply chain or network into an established institution".

\subsection{Sector spanning level systems}

Most unsolved level is the sector spanning system, because of the complexity of the agrifood networks. Different kinds of information from different actors of different chains make difficult the information flow "from the farm to the table of the consumer".

In a review paper Opara introduces the generally applied concepts of the supply chain management and traceability in the agrifood industry (Opara, 2003). He interpreted the definition of the traceability as a preventive strategy of the food quality and safety management. Opara calls the attention to the need of technological innovations in traceability system implementation (product identification, process characterization, information capture, etc.). He mentions the work of Calder and Marr as an example for a specialized standard based initiative and ICT solution, presented in the beef production (Calder and Marr, 1998). Although the aims and the introduced methods are useful, it seems only "wishful design" regarding to the entire chain traceability. 
Wolfert et al. describe explicitly, that a sector spanning system has not yet been developed (Wolfert et al., 2010). It seems, that authors make an effort to outline a really sector spanning ICT method. The detailed conception follows later in the next chapter.

Schiefer highlights, that because of food chain complexity, enterprises cannot solve the whole chain problem alone, but it requires concerted action (Schiefer, 2008). According to the author's opinion, feasible and workable solutions require agreements between the different actors and sectors. Schiefer emphasizes, that information system concept is the strategic development perspective. He also highlights the well known fact, namely that identification of product units, as well as the monitoring and documentation of their movements is an easy to solve conceptual problem in case of a simple serial production, when it does not affected by the composition of various raw materials. In contrary, in the most cases, productions involve e.g. portioning or mixing elements and make difficult the identification and the information flow. Considering this, the author proposes, that a sector might be forced to enter a step-by-step development path that builds on individual development clusters of innovator enterprises, instead of identifying and implementing a comprehensive best solution.

\section{Sector spanning modeling and computation}

There are lots of ICT based solutions in the field of traceability. However, these ICT systems mainly offer certified solutions only for the individual actors of the food chain. Entire chain solutions are usually not frequent or they are in only a test phase, perhaps used only for a sector of the food chain (e.g. beef). Accordingly, the compilation of the entire chain is almost impossible.

Wolfert et al. has been made an effort to outline an ICT solution to manage the information in agrifood supply chain networks (Wolfert et al., 2010). Authors describe unambiguously (in 2010!), that an overall method for analysis, design and implementation of information integration in agrifood chain networks has not yet been developed, that's why it is necessary to develop such a comprehensive method. They call the attention that ICT in the agrifood sector could help to organize and rationalize the large amounts of data, could make the knowledge accessible and, finally, could help to utilize the knowledge in models. In the first part of the study, authors outline the organizational basis of the development. They distinguish the following phases in the development of an overall ICT solution: analysis, basic design and iterative implementation. Analysis means the revelation of the existing software solutions and of the widespread used standardization.

For the systematic analysis of the existing solutions authors use a framework, defined by Giachetti (Giachetti, 2004). According to this framework, there are two integration scopes (intra- and the interenterprise scope), and four information integration types (process, application, data and physical integration).

Authors elaborate the conceptual framework by implementing existing standards, with respect to these two scopes and the four types. According to their opinion, there are the following fields of standardizations:

1. Physical integration standardization

2. Data integration standardization

3. Application integration standardization

4. Process integration standardization

According to authors, final type is the integration of processes. They listed some well-known integrated intra-enterprise models (e.g. CIMOSA, GERAM, etc.).

On the basis of the above analysis, authors highlight, that every single actor of the food chain networks must implement one standard system, as well as have to develop customized communication interfaces, and adopt integration standards.

Following the authors' thoughts, having finished the analysis, the next step is the basic design of the core structure, which covers the conceptual technical architecture, the generic reference information model, the technical communication infrastructure and the institutional organization. Considering the technical architecture, authors planned to develop it on the basis of the SOA (serviceoriented architecture). SOA is a little bit ill-defined software architecture, where functionalities are 
grouped around business processes and packaged as interoperable services. Generic reference information models (actor models, business process models or data models) are also supported by SOA.

The next step of the development is the iterative implementation of the basically designed elements in Living Lab approach. Living Lab (LL) is an open, user-centric innovation approach; it provides a frame for characterizing enterprise solutions. Authors apply the described method through the example of the Dutch arable farming sector.

Setboonsarng, Sakai and Vancura highlight the importance of ICT systems in food chains to improve consumers' confidence and fulfil documentation requirements (Setboonsarng et al., 2009). Authors examine the institutional arrangements, hardware and software requirements and the cost of operations through two food processing examples.

\subsection{Model based simulation of agrifood process networks}

In our understanding, an outside intelligence center with an overall generic knowledge about the participants of the chain can make possible the sector spanning treatment of the whole chain or network. On the basis of the essential and easily adaptable knowledge, the utilization of the data in an upper level simulation model could support the effective tracing of the potential components (e.g. toxins), with case specific analytical capabilities, including the preparation of various case studies.

The model based simulations in the literature are mainly isolated works, with special regards to a narrow field of the agrifood chain.

For example, in the study of Busato and Berruto, authors establish a discrete event dynamic simulation model using Extendsim (Busato and Berruto, 2009). Their aim is to study the different scenarios for the recall procedure, in case of the non-conform perishable production (fruit and vegetable supply chain). Authors describe the model framework and demonstrate one practical example. Although the elaborated case study is correct and useful, the applied solution is not applied widespread and not standardized. That is why the elaborated solution cannot be a general tool for sector spanning traceability. Similarly to other specialists (Golan et al., 2004; Bevilacqua et al. 2009), Busato and Berruto emphasize, that the use of traceability systems could be a cost saving tool, not just for the firm, but for the whole supply chain. However, they consider supply chain logistic systems to be the part of the traceability system, in contrary with many other authors, e.g. Golan.

Considering specific fields, McMeekin et al. in a review study introduce databases, which keep information about microorganisms, and use application softwares to extract information from these databases (McMeekin et al., 2006).

\subsection{Important interactions with logistic and economy}

Traceability system means much more than a simple identification system or tracking of the materials along the process stages. There are references in the literature to the interactions with logistic (supply chain management, inventory management) and economy (added value analysis, identification of hidden resources and deficiencies).

Golan et al. describe in a study of the USDA Economic Research Service, where traceability is only one element of a supply management or a quality/safety control system (Golan et al., 2004). Authors highlight, that traceability system (as a part of the supply chain management system) can be an efficient tool to reduce supply management cost, by means of the reduction of movement, storage, control or recall costs.

Montanari writes about cold chain management systems, from a managerial point of views (Montanari, 2008). Author emphasizes, that for example the time/temperature control becomes a critical issue in the fresh food logistic, and the efficient and effective tracking of cold chain conditions is also one of the main problems to be solved.

Fritz and Schiefer write about the decision complexity and about the aspects of the higher level traceability in their paper (Fritz and Schiefer, 2009). According to their opinion, actors' decision needs 
a balance between consideration of interests, benefits and costs. This balance is difficult to be reached, because of lack in transparency, differences in perception, differences in decision behavior and the complexity of decision scenario. Authors emphasize that decision on the establishment of a tracking and tracing scheme is not just a logistic problem, rather it is a higher management question to identify business interests and realize opportunities within the multi-dimension domain of interests. They also highlight that actors need a differentiated view in tracing and tracking schemes, which points beyond the implementation of tracing and tracking functionalities. In authors' opinion, the real value of traceability systems comes from the combination with production and logistic processes. These complex systems keep the potential resources of deficiencies in backward tracing or the number of potentially affected products in forward view. In this way, authors lay the functionalities of tracing and tracking systems in a higher context of enterprise management.

Minegishi and Thiel also describe, that traceability overlaps with the area of supply chain control and management (Minegishi and Thiel, 2000).

Alfaro and Rábade highlight in their works, that traceability system means much more than the way of food safety guarantee (Alfaro and Rábade, 2009). It means rather "an optimal way of knowing at all times what is happening along the whole supply chain”.

In a paper of Bevilacqua, added value analysis works together with the process identification and tracing by the activity-based costing method (Bevilacqua et al., 2009). As a consequence, the authors dedicate traceability systems not only for a tool of controlled and safety products, but for a technical tool for managing the coordination of the control and documentation of the processes.

\subsection{Case studies from various sectors}

There are lots of publications and case studies from the various sectors. For example, Hoffmann and Doluschitz introduce the improvement of an information management system in organic pork production chains (Hoffmann and Doluschitz, 2009). The aim of the authors is to emphasize the importance of internal, as well as the external information management, according to the specialty of organic pig production in Germany. At first, authors analyze the current state of structure, framework and information management in several European countries. Afterwards, obvious results are observed from the detailed case studies.

Rogge and Becker describe the aims of the IT FoodTrace project, which tends to establish a traceability system for the entire food chain, through the example of the meat sector (Rogge and Becker, 2009). Authors analyze the structure of the meat supply chain and the product flow, regarding to the food service industry.

Doluschitz and Engler write also about traceability systems in the meat sector (Doluschitz and Engler, 2009). Authors analyze the current situation, and determine the aims of an IT system development, in accordance with the German national IT FoodTrace project. They emphasize, that open source communication standards (e.g. agroXML or ISOagriNET) have a keynote role in the development.

Setboonsarng et al. investigate in two case studies, how ICT can help to establish an efficient traceability system, and moreover, improve consumers' confidence in the product (Setboonsarng et al., 2009). Authors consider that Japanese traceability systems are relatively advanced, that's why case studies can be useful for the developing countries.

Schwägele writes about the European perspective of traceability, with special regard to the meat and meat products (Schwägele, 2005). Author details the species identification technologies, as well as the available methods of the geographical origin and fraud detection determination. Smith et al. describe the US perspectives of traceability, mainly in the meat sector, too (Smith et al., 2005). Beulens et al. analyze the challenges of the food safety and transparency, and introduce an oversimplified example to the poultry egg production (Beulens et al., 2005). Montanary analyzes traceability systems, regarding to the chilled and frozen foods, called cold chain (Montanari, 2008). Minegishi and Thiel describe an example application in the field of poultry production, to analyze the consequences of dioxin infection through the supply chain (Minegishi and Thiel, 2000). Skoglund and 
Dejmek introduce a fuzzy traceability system through a realistic example of a dairy process line (Skoglund and Dejmek, 2007). Souza-Monteiro and Caswell study the adaptation of a traceability system at farm level, and analyze the Portuguese pear industry (Souza-Monteire and Caswell, 2009). $\mathrm{Li}$ et al. introduce the implementation of a PDA based record keeping and management information system (Li et al., 2010), by the example of an agricultural case study (cucumber production).

\section{Up-to-date issues and visions}

Recent papers still discuss mainly the chance of an appropriate framework for a chosen part of the chain, realized by various approaches. There are isolated efforts to entire network solutions.

For example, Bevilacqua et al. introduce a computerized system for the traceability of material and information flows, based on an event-driven process chain methodology, combined with the entityrelationship model and with the activity-based costing (Bevilacqua et al., 2009). On the basis of the current state analysis, authors design a future system, through the example of the fourth range vegetable production chain. The example starts from seed production, covers the stages of cultivation and processing, and ends with the marketing of the product.

Fritz and Schiefer analyze the decision situations, involving enterprises and sectors, and summarize results in a cost-benefit table, that provides basis for future developments (Fritz and Schiefer, 2009). They make a statement that tracing and tracking can only be effective, if it is implemented as a sector encompassing system approach.

In a 2009 paper Alfaro and Rábade show, how a traceability system can be more than a way to guarantee food safety (Alfaro and Rábade, 2009). Authors illustrate their results through an example of a Spanish vegetable firm. They also describe how the established traceability system provides advantages for the firms along the stages of their activities.

Authors concluded that the exemplary implemented internal computerized system provided appropriate real-time traceability information.

Thakur and Hurburg analyze also an internal traceability system through the example of a bulk grain supply chain (Thakur and Hurburg, 2009). They describe a case study about implementation of a special internal system. Specialties of the grain lots are coming from the problem of lots identity, caused by the various mixing along the processes. First, authors define the needs of actors along the chain, and then, they develop a model for implementing the internal system for a grain elevator that handles specialty of these chains. The developed model shows, what grain lot information should be recorded, and then pass it to the following actor of the chain. Finally, authors discuss some information exchange technologies (e.g. XML) to enable, transfer and share the grain supply chain information.

Souza-Monteiro and Caswell analyze the adoption of traceability schemes at farm level, through the example of Portuguese pear industry (Souza-Monteiro and Caswell, 2009). Authors highlight that this group of actors are mainly sensitive for the cost of traceability scheme implementation. They analyze in the study, how different factors (e.g. farm size, production, productivity, farmer's age or education) are related to traceability adoption.

Wolfert et al. emphasize, that because of increasing demands on safety and quality foods, actors of the food and feed chains continuously have to work on innovations of products, processes and ways of cooperation in agrifood supply chain networks (Wolfert et al., 2010). They mention that traditional software engineering approaches are inadequate to address these issues. That's why authors provide an overall methodology for analysis, design and implementation of information integration. Development of the method based on the Dutch arable farming sector, from the basic research of the method till a systematic and sustainable ICT development. The technical architecture and infrastructure of the introduced system are based on the service-oriented architecture (SOA) and the Live Lab approach.

Ruiz-Garcia et al. in a 2010 paper propose a web-based system, and test it by the implementation of a prototype system (Ruiz-Garcia et al., 2010). Their system is based on the SOA architecture, and in this solution clients also communicate with XML messages. The prototype software client was written 
in the Python language, and the graphical user interface was made with Zope. Authors concluded, that the established system fulfils Kim's before mentioned criteria, but in this solution succeeds only the one step up, one step down principle, and there is not a global transparency over the process network.

In one hand, in spite of the need for an entire chain system, recent studies offer different results for only a part of the chain. The island-like developments of the various software solutions are keep back the connections of the actors. On the other hand, the complexity, the holistic nature of the food chains and the different character of the actors up to now detained the evolution of an easy-usable, general, sector-spanning system. Although there are some examples for the entire chain and sector spanning systems, these became not generally applied in the world.

In line with the safety and quality food production, another important question is the world level sufficient amount of food production. International Food Policy Research Institute (http://www.ifpri.org) has been elaborated the 2020 initiative. It contributes to developing a consensus for action through generating policy information and supporting policy consultations. During the past year, the Initiative focused on two main projects, the Agriculture and Climate Change, and the Millions Fed subproject.

The European Technology Platform on Food for Life also published a Vision for 2020 and beyond (http://etp.ciaa.be/asp/home/welcome.asp). It has been worded in Brussels in 2005. The vision of the ETP on Food for Life is that an effective integration of concerted research in the nutritional, food and consumer sciences and food chain management will deliver innovative and improved food products for national, regional and global markets, in accordance with consumers' demands and expectations. These results, together with recommended changes in dietary regimes and lifestyles, will have a positive impact on quality of life and on public health.

\section{Conclusions}

Having reviewed the huge amount of information, open questions still remain to be answered. The most fundamental ones are the followings:

- Are there really workable sector spanning methodologies?

The answer is there are not at all. Nevertheless, the field experts and the computer modeling community seems to be prepared to develop quite new tools in the near future.

- How can computational methods contribute to (i.e. partially replace for) the analytical measurements?

Obviously we ought to find a reasonable compromise between the "Schylla" of the simple step by step passing of traceable unit IDs for the neighboring actors, and the "Carybdis" of collecting enormously huge databases, containing every relevant data of the actors.

- Which functionalities can be solved by (an optional network of) the sector spanning outside intelligence centers?

The future role of the sector spanning, outside intelligent centers is the traceability and trackability service for the actors on cooperative basis of the mutual interests. In addition, the centers have to support the global supply chain and value chain management, as well as the work of the authorities, that are responsible for the human health.

In the following part of our work, we shall outline a sector spanning system. This study will describe the planned development, based on our research group's methodology, in detail.

\section{References}

Alfaro, J.A, L. A. Rábade. 2009. Traceability as a strategic tool to improve inventory management: A case study in the food industry. Int. J. Production Economics, 118: 104-110.

Bertolini, M., M. Bevilacqua, R. Massini. 2006. FMECA approach to product traceability in the food industry. Food Control, 17: 137-145.

Beulens, A. J. M., D. F. Broens, P. Folstar, G. J. Hofstede. 2005. Food safety and transparency in food chains and networks. Relationships and challenges. Food Control, 16: 481-486. 
Bevilacqua, M., F. E. Ciarapica, G. Giacchetta. 2009. Business process reengineering of a supply chain and a traceability system: A case study. Journal of Food Engineering, 93: 13-22.

Busato, P., R. Berruto. 2009. Use of simulation models to study the dynamic of recall of non-conform perishable produce through the supply chain. $3^{\text {rd }}$ International European Forum on "System Dynamics and Innovation in Food Networks”, Innsbruck-Igls, Austria, 16-20 February 2009.

Calder, R., P. Marr. 1998. A beef producer initiative in traceability: Scottish Boarders TAG. Supply Chain Mtg., 3(3): 123-126.

Doluschitz, R., B. Engler. 2009. Traceability of foods of animal origin. In: EFITA conference '09. Proceedings of the 7th EFITA Conference, 605-613. Wageningen: Wageningen Academic Publishers, EFITA conference '09.

Dupuy, C., V. Botta-Genoulaz, A. Guinet. 2005. Batch dispersion model to optimize traceability in food industry. Journal of Food Engineering, 70: 333-339.

Fritz, M., G. Schiefer. 2009. Tracking, tracing and business process interests in food commodities: A multi-level decision complexity. Int. J. Production Economics, 117: 317-329.

Füzesi, I., M. Herdon. 2007. EDI - XML Standards and Technologies in the Agri-Food Industry. Summer University on IT in Agriculture and Rural Development 2007, Debrecen, Hungary

Giachetti, R. E. 2004. A framework to review the information integration of the enterprise, International Journal of Production Research, 42: 1147-1166.

Golan, E., B. Krissoff, F. Kuchler. 2004. Food Traceability: one ingredient in a safe and efficient food supply. USDA Economic Research Service, Amber Waves 2(2): 14-21.

Herdon, M., I. Füzesi. 2006. Quality Control And Product Tracing In ERP Systems. $4^{\text {th }}$ World Congress on Computers in Agriculture 2006, 24-26 July, Lake Buena Vista, Florida, USA

Hoffmann, C., R. Doluschitz. 2009. Improving information management in organic pork production chains. In: EFITA conference '09. Proceedings of the 7th EFITA Conference, 627-633. Wageningen: Wageningen Academic Publishers, EFITA conference '09

Jansen-Vullers, M. H., C.A. van Dorp, A. J. M. Beulens. 2003. Managing traceability information in manufacture. International Journal of Information Management, 23: 395-413.

Kim, H. M., M. S. Fox, M. Gruniger. 1995. An Ontology of Quality for Enterprise Modeling. IEEE Proceedings of WET-ICE, 105-116. Los Albamitos, CA, USA.

Li, M., J. P. Qian, X. T. Yang, C. H. Sun, Z. T. Ji. 2010. A PDA-based record-keeping and decisionsupport system for traceability in cucumber production. Computers and Electronics in Agriculture, 70: 69-77.

McMeekin, T. A., J. Baranyi, J. Bowman, P. Dalgaard, M. Kirk, T. Ross, S. Schmid, M. H. Zwietering. 2006. Information systems in food safety management (review). International Journal of Food Microbiology, 112: 181-194.

Minegishi, S., D. Thiel. 2000. System dynamics modeling and simulation of a particular food supply chain. Simulation Practice and Theory, 8: 321-339.

Montanari, R. 2008. Cold chain tracking: a managerial perspective. Trends in Food Science and Technology, 19: 425-431.

Opara, L. U. 2003. Traceability in agriculture and food supply chain: A review of basic concepts, technological implications, and future prospects. Food, Agriculture \& Environment, 1(1): 101-106.

Peres, B., N. Barlet, G. Loiseau, D. Montet. 2007. Review of the current methods of analytical traceability allowing determination of the origin of foodstuffs. Food Control, 18: 228-235. 
Rogge, C. B. E., T. C. Becker. 2009. A traceability system for the food service industry. In: EFITA conference '09. Proceedings of the 7th EFITA Conference 615-625. Wageningen: Wageningen Academic Publishers, EFITA conference '09

Ruiz-Garcia, L., G. Steinberger, M. Rothmund. 2010. A model and prototype implementation for tracking and tracing agricultural batch products along the food chain. Food control, 21: 112-121.

Schiefer, G. 2008. Tracing and Tracking - A Challenge for System Organization and IT. Journal of Information Technology in Agriculture, 3: 19-25.

Schwägele, F. 2005. Traceability from a European perspective. Review. Meat Science, 71: 164-173.

Setboonsarng, S., Sakai, J., Vancura, L.: Food Safety and ICT Traceability Systems: Lessons from Japan for Developing Countries. ADBI Working Paper 139. Tokyo: Asian Development Bank Institute, 2009. Available: http://www.adbi.org/working-paper/2009/05/28/3012.ict.food.traceability. system/

Skoglund, T., P. Dejmek. 2007. Fuzzy traceability: a process simulation derived extension of the traceability concept in continuous food processing. Food and Bioproducts Processing, 85(4): 354-359.

Smith, G. C, J. D. Tatum, K. E. Belk, J. A. Scanga, T. Grandin, J.N. Sofos. 2005. Traceability from a US perspective. Review. Meat Science, 71: 174-193.

Souza-Monteiro, D. M, J. A. Caswell. 2009. Traceability adoption at the farm level: An empirical analysis of the Portuguese pear industry. Food Policy, 34: 94-101.

Thakur, M., C. R. Hurburg. 2009. Framework for implementing traceability system in the bulk grain supply chain. Journal of Food Engineering, 95: 617-626.

Wolfert, J., C. N. Verdouw, C. M. Verloop, A. J. M. Beulens. 2010. Organizing information integration in agri-food - A method based on a service-oriented architecture and living lab approach. Computers and Electronics in Agriculture, 70(2): 389-405. 